Jurnal Ilmu Sosial dan Pendidikan (JISIP)

Vol. 5 No. 3 Juli 2021

Terakreditasi Peringkat 5 (No. SK: 85/M/KPT/2020)

e-ISSN : 2656-6753, p-ISSN: 2598-9944

DOI: 10.36312/jisip.v5i3.2195 /http://ejournal.mandalanursa.org/index.php/JISIP/index

\title{
Filsafat Ilmu Pendidikan Islam Dalam Perspektif Pendidikan Jasmani
}

\author{
Sri Budiman ${ }^{1}$, Abdul Wachid Bambang Suharto ${ }^{2}$ \\ ${ }^{1}$ Mahasiswa Pascasarjana Manajemen Pendidikan Islam, UIN Prof. K.H. Saifuddin Zuhri, Purwokerto \\ ${ }^{2}$ Dosen Pascasarjana Manajemen Pendidikan Islam, UIN Prof. K.H. Saifuddin Zuhri, Purwokerto
}

\begin{abstract}
Article Info
Article history:

Article Reseived : 12 July 2021

Publication: 16 July 2021
\end{abstract}

\section{Keywords:}

Filsafat ilmu, Pendidikan islam

Pendidikan jasmani

\begin{tabular}{l}
\hline Article Info \\
\hline Article history:
\end{tabular}

Artikel diterima : 12 Juli 2021

Publikasi : 16 Juli 2021

\begin{abstract}
Pendidikan Islam merupakan ilmu yang mengajarkan manusia untuk menjadi lebih baik. Manusia juga membutuhkan jasmani yang sehat untuk bertahan hidup. Oleh karena itu, perlu dikaji materi mengenai filsafat ilmu pendidikan Islam dalam perspektif pendidikan jasmani. Manusia memerlukan ilmu untuk dapat memecahkan setiap persoalan dalam hidup. Ilmu yang sangat erat kaitannya dengan kehidupan yaitu ilmu pendidikan Islam. Ilmu pendidikan Islam mengajarkan hidup sesuai dengan nilai Islam. Pemimpin dalam kehidupan harus memiliki kesehatan jasmani dan mental yang kuat untuk dapat mengatasi berbagai permasalahan. Upaya dalam meningkatkan kesehatan jasmani dapat dilakukan dengan mempelajari pendidikan jasmani. Umat Islam sejak dulu sampai sekarang telah menerapkan pendidikan jasmani dalam mempelajari dan membela Islam. Landasan religius dalam pendidikan jasmani berdasarkan Al Quran dan hadits membuktikan bahwa pendidikan agama Islam saling berhubungan dengan pendidikan jasmani dan saling melengkapi satu sama lain dalam mendukung kehidupan manusia sebagai khalifah di bumi.
\end{abstract}

Abstract
Islamic education is a science that teaches people to be better. Humans also need a
healthy body to survive. Therefore, it is necessary to study the material on the
philosophy of Islamic education in the perspective of physical education. Human
beings need knowledge to be able to solve every problem in life. Science that is very
closely related to life is the science of Islamic education. Islamic education teaches
life in accordance with Islamic values. Leaders in life must have strong physical and
mental health to be able to overcome various problems. Efforts in improving physical
health can be made by studying physical education. Muslims have long since applied
physical education in learning and defending Islam. The religious foundation in
physical education based on the Quran and hadith proves that Islamic religious
education is interconnected with physical education and complements each other in
supporting human life as caliphs on earth.
This is an open access article under the Lisensi Creative Commons Atribusi-BerbagiSerupa 4.0
Internasional

\section{Corresponding Author:}

\section{Sri Budiman}

Universitas Islam Negeri Prof. K. H. Saifuddin Zuhri

Email: budimansri75@gmail.com

\section{PENDAHULUAN}

Manusia merupakan mahkluk yang paling sempurna yang diciptakan oleh Allah SWT. Ketika manusia lahir, dia mulai mengenal dirinya, kemudian mengenal alam sekitarnya, dan pada akhirnya mulai timbul berbagai macam pertanyaan mengenai darimana, bagaimana dan untuk apa sesuatu diciptakan. Ilmu yang mempelajari tentang bagaimana asal usul mengenai suatu objek disebut sebagai ilmu filsafat. Abad ke-20 sering disebut sebagai abad ilmu dan teknologi. Dalam 
perkembangannya, ilmu pengetahuan dan teknologi telah dikembangkan demi kesejahteraan umat manusia. Namun pada kenyataannya, ilmu pengetahuan dan teknologi menjadi alat untuk merusak manusia itu. Hal tersebut disebabkan karena kurangnya manusia dalam memahami makna dan tujuan dari ilmu itu sendiri. Ilmu yang banyak menjadi perdebatan dalam kehidupan manusia yaitu mengenai ilmu agama. Ilmu agama yang banyak diajarkan di sekolah-sekolah disebut sebagai pendidikan agama. Agama Islam adalah agama yang paling banyak penganutnya sehingga dalam praktiknya perlu dilakukan studi pustaka lebih lanjut mengenai ilmu pendidikan Islam.

Pendidikan Islam pada dasarnya merupakan ilmu yang mengajarkan manusia untuk menjadi manusia yang sempurna dalam segala hal. Dalam meraih tujuan ini, maka pelaksanaannya harus sepenuhnya bersumber dari cita-cita yang diwahyukan Allah SWT dan sunah Nabi Muhammad SAW. Islam sebagai pembawa misi rahmatan lil alamin sangat menekankan manusia agar melaksanakan amanahnya untuk memaksimalkan potensinya sebagai kodratnya menjadi khalifah di bumi. Sebagai makhluk yang paling sempurna, Allah menitipkan kepada manusia beberapa aspek seperti akal untuk berfikir, hati untuk berbudi, dan kesehatan jasmani untuk berkreasi.

Jasmani merupakan salah satu aspek yang tidak kalah penting dalam diri manusia. Kemampuan jasmani manusia untuk melaksanakan segala kegiatan perlu ditingkatkan, termasuk beribadah. Sebagai contoh yaitu ketika umat Islam berjuang untuk berdakwah dan membela agama Islam dijaman dahulu, mereka berusaha untuk melatih jasmani agar dapat berperang melawan musuh yang menentang agama Islam. Pendidikan jasmani diperlukan untuk mendukung aspek lain seperti rohani pada manusia. Jasmani dan rohani pada manusia berjalan saling berdampingan dan saling melengkapi. Jika rohani manusia sehat tetapi jasmaninya sakit, maka manusia tidak akan sempurna dalam menjalani aktivitasnya. Makna pendidikan jasmani dalam pendidikan Islam perlu dipelajari lebih lanjut agar manusia lebih memahami pentingnya pendidikan jasmani dalam pendidikan Islam. Oleh karena itu, perlu dikaji materi mengenai pendidikan Islam dalam perspektif pendidikan jasmani.

\section{METODE PENELITIAN}

Penelitian ini merupakan jenis penelitian kualitatif. Penelitian kualitatif yaitu penelitian yang hasilnya dituliskan dalam bentuk kata-kata, bukan dalam bentuk angka. Penelitian ini dilakukan di UIN Prof. K. H. Saifuddin Zuhri selama enam bulan, mulai dari bulan Januari sampai Juni 2021. Target/sasaran dalam penelitian ini yaitu manajemen strategik pendidikan islam yang terjadi di Indonesia. Sedangkan subjek penelitian ini yaitu para pelaksana pendidikan islam. Prosedur dalam penelitian yaitu mengkaji beberapa sumber yang terkait dengan manajemen strategik pendidikan islam di Indonesia, kemudian memilih dan mengaitkan beberapa sumber tersebut untuk dijadikan sebagai argumen baru dari argumen yang sudah ada sebelumnya.

Karya tulis ini menggunakan metode studi kepustakaan (library research). Studi kepustakaan merupakan suatu studi yang digunakan dalam mengumpulkan informasi dan data dengan bantuan berbagai macam material yang ada di perpustakaan seperti dokumen, buku, majalah, serta kisah-kisah sejarah (Creswell, 2015). Studi kepustakaan juga dapat mempelajari beberbagai buku referensi serta hasil penelitian sebelumnya yang sejenis yang berguna untuk mendapatkan landasan teori mengenai masalah yang akan diteliti. Studi kepustakaan juga berarti teknik pengumpulan data dengan melakukan penelaahan terhadap buku, literatur, catatan, serta berbagai laporan yang berkaitan dengan masalah yang ingin dipecahkan. Sedangkan menurut ahli lain studi kepustakaan merupakan kajian teoritis, referensi serta literatur ilmiah lainnya yang berkaitan dengan budaya, nilai dan norma yang berkembang pada situasi sosial yang diteliti.

Data adalah kenyataan, fakta, atau bahan yang digunakan untuk menyusun hipotesa (Partanto \& Al-Barry, 1994). Sumber data yang menjadi bahan penelitian ini berupa buku, jurnal dan situs internet yang terkait dengan manajeemen strategik pendidikan islam. Teknik pengumpulan data dalam penelitian ini yaitu dengan dokumentasi. Dokumentasi dilakukan dengan mencari data mengenai hal-hal atau variabel yang berupa catatan, buku, makalah atau artikel, dan jurnal. 
Teknik analisis data yang digunakan dalam penelitian ini adalah metode analisis isi (content analysis). Analisis ini digunakan untuk mendapatkan inferensi yang valid dan dapat diteliti ulang berdasarkan konteksnya (Krippendorff, 1993). Dalam analisis ini akan dilakukan proses memilih, membandingkan, menggabungkan dan memilah berbagai pengertian hingga ditemukan yang relevan. Untuk mencegah serta mengatasi kesalahan pengertian manusiawi yang bisa terjadi karena kekurangan penulis pustaka maka dilakukan pengecekan antar pustaka dan memperhatikan komentar pembimbing.

\section{HASIL PENELITIAN DAN PEMBAHASAN}

\subsection{Hasil Penelitian}

\subsubsection{Pentingnya Filsafat Ilmu Bagi Kehidupan}

Filsafat ilmu adalah filsafat yang mempelajari tentang hakikat pelaksanaan suatu ilmu. Hakikat pelaksanaan suatu ilmu meliputi latar belakang, tujuan, cara, dan hasil pendidikan mengenai suatu topik. Metode yang dilakukan dalam filsafat ilmu yaitu mempelajari secara kritis struktur dan manfaat pendidikan. Filsafat ilmu dapat digunakan oleh manusia untuk mengatasi persoalannya di kehidupan, baik persoalan diri sendiri, orang lain, maupun persoalan mengenai alam sekitar dan penciptanya.

Menurut perspektif sejarah, berbagai macam ilmu mengalami perkembangan yang sangat pesat. Ilmu yang berkembang adalah ilmu yang terkait dengan kehidupan sehari-hari misalnya ilmu kedokteran, pertanian, perikanan, dan matematika. Meskipun perkembangan ilmu terjadi cukup pesat sejak jaman dahulu, akan tetapi tetap diperlukan pengembangan ilmu lebih lanjut agar tercipta penemuan baru yang berguna bagi kehidupan manusia (Saryono, 2018). Saat ini, telah banyak usaha yang dilakukan dalam pengembangan ilmu seperti pembuatan taman baca, pembagian buku gratis, dan memberikan bantuan pendidikan. Sebagai contoh yaitu Rumah Kreatif Wadas Kelir berhasil meningkatkan kesejahteraan relawan dan masyarakat sekitar sebagai wujud dari usaha pengembangan ilmu pendidikan (Naqiyah, Wachid Bambang Suharto, \& Supriyanto, 2019). Dalam pandangan Islam, ilmu memiliki banyak fungsi diantaranya:

1. Sarana paling utama menuju taqwa

2. Amalan yang tidak terputus pahalanya

3. Pondasi utama sebelum berkata dan beramal

4. Sebagai kebutuhan rohani

5. Salah satu bentuk metode tarbiyah umat agar tidak menjadi alat permainan iblis

\subsubsection{Pendidikan Islam}

Pendidikan dalam pengertiannya dapat ditinjau dari berbagai sudut pandang para ahli, yaitu dapat dilihat dari berbagai sisi, diantaranya menurut para ahli dalam pendidikan Islam, filsafat, sosiologi, psikologi, fisiologi, olahraga dan kesehatan (Mujahir, 2015). Islam memahami istilah pendidikan dengan dua sudut pandang yaitu yang pertama dari segi lughat (bahasa) yang terdiri dari empat istilah yaitu tarbiyah, ta'lim, tadris dan ta'dib, dan yang kedua dari segi istilah yaitu dengan pendapat beberapa ahli pendidikan Islam (Ma'zumi, Syihabudin, \& Najmudin, 2019). Menurut tarbiyah, pendidikan memiliki makna yaitu mengasuh, memberi pendidikan, dan merawat. Menurut ta'lim, pendidikan memiliki makna yaitu memberi suatu ilmu pengetahuan. Menurut ta'dib, pendidikan memiliki makna yaitu memberi adab dan mendidik dalam bentuk tingkah laku. Menurut tadris, pendidikan memiliki makna yaitu menyebutkan secara berulang-ulang agar dapat dipahami. Menurut istilah, pendidikan mengalami perubahan dengan interpretasi dari kalangan intelektual Islam maupun non Islam.

Ilmu pendidikan Islam adalah sistem pendidikan yang memberikan kemampuan seseorang untuk memimpin kehidupannya sesuai dengan cita-cita dan nilai Islam yang telah menjiwai dan mewarnai corak kepribadiannya. Dengan kata lain pendidikan Islam adalah 
suatu sistem kependidikan yang mencakup seluruh aspek kehidupan yang dibutuhkan yang dibutuhkan oleh hamba Allah sebagaimana Islam telah menjadi pedoman bagi seluruh aspek kehidupan manusia baik duniawi maupun ukhrawi. Manusia sebagai khalifah di bumi wajib mempelajari hal-hal yang berhubungan dengan ketaqwaan terhadap Tuhan agar tercipta keseimbangan, baik dalam kehidupan maupun alam.

Ilmu pendidikan Islam mempunyai cakupan yang sangat luas. Objek ilmu pendidikan Islam ialah situasi pendidikan yang terdapat pada dunia pengamalan. Didalamnya terdapat pihak-pihak yang ikut terlibat baik secara langsung maupun tidak langsung. Ilmu pendidikan Islam dapat mendorong seseorang untuk lebih mengerti diri sendiri dan menjadi pedoman dalam aktualisasi diri. Sifat paling dominan dari aktualisasi diri adalah sifat spontanitas, kesederhanaan, alami, jujur, tidak dibuat-buat dan terbuka.

\subsubsection{Pendidikan Jasmani}

Pendidikan jasmani memiliki arti sebagai penyeimbang rohani dalam tubuh manusia karena jasmani dan rohani merupakan dua aspek tubuh yang tidak bisa terlepas satu sama lain (Kahar, 2018). Secara umum, pendidikan jasmani dapat diartikan sebagai pembangkitan kekuatan yang terpendam atau mengaktifkan kekuatan potensi tubuh dengan cara mengelola dan merubahnya. Di sekolah sering kali dibahas mengenai pendidikan jasmani yang dijadikan sebagai suatu kebutuhan dalam meningkatkan kebugaran dan kekuatan fisik. Pendidikan jasmani merupakan kegiatan yang mutlak bagi pengembangan jasmani dan mental.

Seiring dengan berkembangnya jaman, kata "pendidikan jasmani" mengandung pengertian mendidik. Istilah ini menaikkan martabat pendidikan jasmani menjadi setaraf dengan pendidikan intelektual dan mental (Siti Maesaroh, 2017). Lalu, semakin diakui di kalangan para pendidik bahwa pendidikan yang bulat hanya dapat dicapai jika tercakup di dalamnya pendidikan jasmani. Kemudian pengertian pendidikan jasmani diubah sebagai olahraga (Mulya et al., 2015). Pada perkembangan terakhir terjadilah penelaah kembali tentang arti olahraga dan mencoba mendudukannya pada proporsi yang lebih riil menurut kemampuan masyarakat dan pemerintah. Oleh karena itu, dapat dikatakan bahwa pendidikan jasmani pada dasarnya merupakan pendidikan melalui aktivitas jasmani untuk mencapai perkembangan individu secara menyeluruh. Namun, perolehan keterampilan dan perkembangan lain yang bersifat jasmaniah itu juga sekaligus sebagai tujuan. Melalui pendidikan jasmani, siswa disosialisasikan ke dalam aktivitas jasmani yang berorientasi pada kesehatan dan kekuatan jasmani seseorang.

Pendidikan jasmani memiliki beberapa fungsi yaitu sebagai olahraga, prestasi, dan pelaksana kegiatan. Fungsi pendidikan jasmani yang pertama yaitu olahraga yang artinya sebagai bentuk pelatihan bagi fisik manusia agar senantiasa memiliki tubuh yang sehat. Fungsi pendidikan jasmani yang kedua yaitu prestasi yang artinya sebagai bentuk kompetisi yang dapat diikuti oleh berbagai macam pihak. Fungsi pendidikan jasmani yang ketiga yaitu pelaksana kegiatan artinya sebagai dasar untuk melatih tubuh manusia agar mampu melaksanakan berbagai kegiatan.

\subsection{Pembahasan}

Pemahaman makna pendidikan dalam Islam lain dengan pandangan pendidikan pada umumnya. Islam memahami istilah pendidikan dengan dua sudut pandang yaitu yang pertama dari segi lughat (bahasa) yang terdiri dari tiga istilah yaitu tarbiyah, ta'lim, dan ta'dib, dan yang kedua dari segi istilah yaitu dengan pendapat beberapa ahli pendidikan Islam. Menurut tarbiyah, pendidikan memiliki makna yaitu mengasuh, memberi pendidikan, dan merawat. Menurut ta'lim, pendidikan memiliki makna yaitu memberi suatu ilmu pengetahuan. Menurut ta'dib, pendidikan memiliki makna yaitu memberi adab dan mendidik dalam bentuk tingkah laku. Menurut istilah, 
pendidikan mengalami perubahan denganinterpretasi dari kalangan intelektual Islam maupun non Islam.

Ilmu pendidikan Islam adalah sistem pendidikan yang memberikan kemampuan seseorang untuk memimpin kehidupannya sesuai dengan cita-cita dan nilai Islam yang telah menjiwai dan mewarnai corak kepribadiannya (Suharto, Waluyo, Pradopo, \& Suyitno, 2017). Dengan kata lain pendidikan Islam adalah suatu sistem kependidikan yang mencakup seluruh aspek kehidupan yang dibutuhkan yang dibutuhkan oleh hamba Allah sebagaimana Islam telah menjadi pedoman bagi seluruh aspek kehidupan manusia baik duniawi maupun ukhrawi. Manusia sebagai khalifah di bumi wajib mempelajari hal-hal yang berhubungan dengan ketaqwaan terhadap Tuhan agar tercipta keseimbangan, baik dalam kehidupan maupun alam (Suharto, Waluyo, Pradopo, \& Suyitno, 2018).

Ilmu pendidikan Islam mempunyai cakupan yang sangat luas. Objek ilmu pendidikan Islam ialah situasi pendidikan yang terdapat pada dunia pengamalan. Didalamnya terdapat pihak-pihak yang ikut terlibat baik secara langsung maupun tidak langsung. Ilmu pendidikan Islam dapat mendorong seseorang untuk lebih mengerti diri sendiri dan menjadi pedoman dalam aktualisasi diri. Sifat paling dominan dari aktualisasi diri adalah sifat spontanitas, kesederhanaan, alami, jujur, tidak dibuat-buat dan terbuka (Frandika, Suroso, \& Suharto, 2019).

Menurut pandangan Islam, jasmani adalah sesuatu yang merasal dari air mani (sperma) dari pihak lelaki dan telur perempuan. Setelah air mani berada di ovum sang ibu, maka terbentuklah jasmani pada bayi. Jasmani merupakan potensi yang perlu dikembangkan dan dilatih agar menjadi utuh dan sempurna. Pengembangan jasmani dilakukan dengan melaksanakan pendidikan jasmani. Ada beberapa landasan ilmu pendidikan jasmani yaitu landasan yang dijadikan pegangan dalam menyelenggarakan pendidikan jasmani. Landasan pendidikan jasmani terdiri dari tiga aspek yaitu religius, yuridis, dan medis.

Landasan religius adalah dasar-dasar yang bersumber dari Islam yang tertera dalam AlQuran, maupun hadits (Lazuardi, 2014). Menurut ajaran Islam, melaksanakan pendidikan Islam merupakan perintah dari Allah SWT dan merupakan ibadah bagi yang menjalankannya. Al-Quran sebagai sumber kebenaran tidak dapat diragukan lagi. Adapun beberapa ayat Al-Quran dan hadits yang terkait dengan pendidikan jasmani yaitu:

\section{Al Quran}

Q.S. Al Baqarah: 247

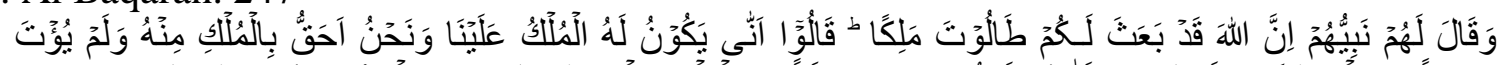

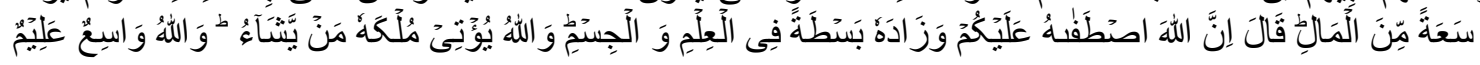
Artinya: "Nabi mereka mengatakan kepada mereka: "Sesungguhnya Allah telah mengangkat Thalut menjadi rajamu." mereka menjawab: "Bagaimana Thalut memerintah Kami, Padahal Kami lebih berhak mengendalikan pemerintahan daripadanya, sedang diapun tidak diberi kekayaan yang cukup banyak?" Nabi (mereka) berkata: "Sesungguhnya Allah telah memilih rajamu dan menganugerahinya ilmu yang Luas dan tubuh yang perkasa." Allah memberikan pemerintahan kepada siapa yang dikehendaki-Nya. dan Allah Maha Luas pemberian-Nya lagi Maha mengetahui”.

Q.S. Al A'raf: 69

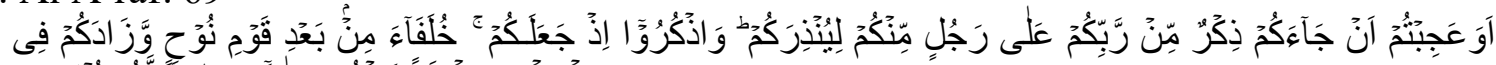

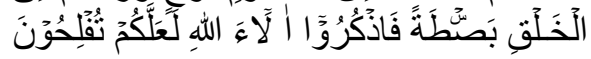

Artinya: "Apakah kamu (tidak percaya) dan heran bahwa datang kepadamu peringatan dari Tuhanmu yang dibawa oleh seorang laki-laki di antaramu untuk memberi peringatan kepadamu? dan ingatlah oleh kamu sekalian di waktu Allah menjadikan kamu sebagai pengganti-pengganti (yang berkuasa) sesudah lenyapnya kaum Nuh, dan Tuhan telah 
melebihkan kekuatan tubuh dan perawakanmu (daripada kaum Nuh itu). Maka ingatlah nikmat-nikmat Allah supaya kamu mendapat keberuntungan."

Q.S. Al Qashash: 26

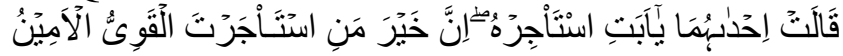

Artinya: "Karena Sesungguhnya orang yang paling baik yang kamu ambil untuk bekerja (pada kita) ialah orang yang kuat lagi dapat dipercaya".

Q.S. An Naml: 39

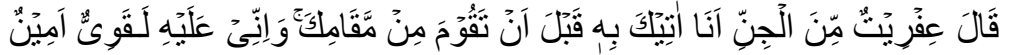

Artinya: "Berkata 'Ifrit (yang cerdik) dari golongan jin: "Aku akan datang kepadamu dengan membawa singgsana itu kepadamu sebelum kamu berdiri dari tempat dudukmu; Sesungguhnya aku benar-benar kuat untuk membawanya lagi dapat dipercaya".

Q.S. As Shad: 34

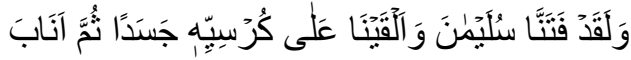

Artinya: "Dan Sesungguhnya Kami telah menguji Sulaiman dan Kami jadikan (dia) tergeletak di atas kursinya sebagai tubuh (yang lemah karena sakit), kemudian ia bertaubat".

Q.S. Al A'raf: 148

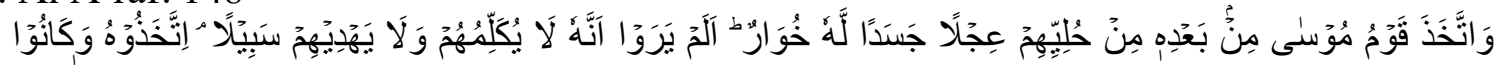
ظلِفِيْنَ

Artinya: "Dan kaum Musa, setelah kepergian Musa ke gunung Thur membuat dari perhiasan-perhiasan (emas) mereka anak lembu yang bertubuh dan bersuara. Apakah mereka tidak mengetahui bahwa anak lembu itu tidak dapat berbicara dengan mereka dan tidak dapat (pula) menunjukkan jalan kepada mereka? mereka menjadikannya (sebagai sembahan) dan mereka adalah orang-orang yang zalim”.

Q.S. Maryam: 10

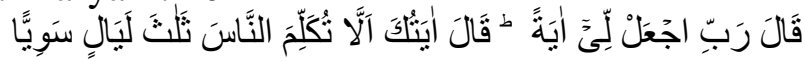

Artinya: "Zakaria berkata: "Ya Tuhanku, berilah aku suatu tanda". Tuhan berfirman:

"Tanda bagimu ialah bahwa kamu tidak dapat bercakap-cakap dengan manusia selama tiga malam, Padahal kamu sehat".

Q.S. Al Isra': 82

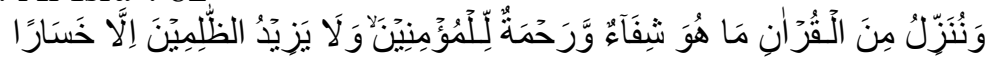

Artinya: "Dan Kami turunkan dari Al Quran suatu yang menjadi penawar dan rahmat bagi orang-orang yang beriman dan Al Quran itu tidaklah menambah kepada orangorang yang zalim selain kerugian."

Q.S. An Nahl: 69

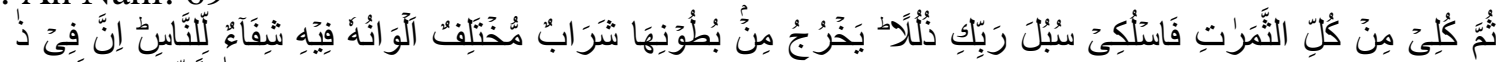

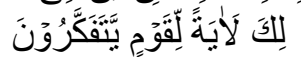

Artinya: "Kemudian makanlah dari tiap-tiap (macam) buah-buahan dan tempuhlah jalan Tuhanmu yang telah dimudahkan (bagimu). dari perut lebah itu ke luar minuman (madu) yang bermacam-macam warnanya, di dalamnya terdapat obat yang menyembuhkan bagi manusia. Sesungguhnya pada yang demikian itu benar-benar terdapat tanda (kebesaran Tuhan) bagi orang-orang yang memikirkan." 
Q.S. Al Anbiya: 8

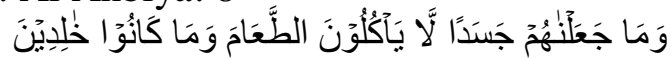

Artinya: "Dan tidaklah Kami jadikan mereka tubuh-tubuh yang tiada memakan makanan, dan tidak (pula) mereka itu orang-orang yang kekal."

\section{Hadits}

Keutamaan bagi orang mukmin yang kuat

"Mukmin yang kuat itu lebih baik dan lebih dicintai Allah daripada mukmin yang lemah, dan di dalam segala kebaikan.” (HR. Muslim).

Berenang dan memanah

"Ajarilah anak-anakmu berenang dan melepaskan anak panah dan ajarilah wanita memintal." (HR. Baihaqi dari Umar ibn al-Khattab).

Mendorong melatih memanah

"Dari Abu 'Aliyah, bahwa Rasulullah Saw melewati beberapa anak muda yang sedang berlatih memanah, lalu Rasulullah Saw bersabda (kepada mereka): "Wahai keturunan Isma'il, memanahlah, karena kakemu seorang pemanah." (HR. Sa'ad bin Manshur dan Bukhari, dari Salamah bin 'Aqwa').

Lomba lari

"Dari 'Abdullah bin Harits as, ia berkata: "Rasulullah Saw membariskan 'Abdullah, Ubaidah, dan banyak lagi orang dari Bani 'Abbas as, lalu bersabda: Barang siapa yang dapat mengejar aku, dia akan akan mendapatkan ini dan itu."” Ia (Abdullah) berkata: "Lalu mereka berlomba mengejar beliau, sehingga mereka dapat memegang punggung dan dada beliau, lalu beliau mencium mereka dan menggandengnya." (HR. Ahmad).

Lomba pacuan kuda

"Dari Ibnu Umar ra, dia berkata, "Nabi Saw memperlombakan kuda yang dipersiapkan untuk pacuan dari Al-Hafya hingga Tsaniyyatul Wada'. Lalu beliau memperlombakan kuda yang tidak dipersiapkan untuk pacuan dari Tsaniyyah hingga masjid bani Zuraiq". Ibnu Umar berkata, "Aku termasuk peserta lomba".

Bermain tombak

"Dari Abu Hurairata ra, dia berkata, "ketika orang-orang Habasyah bermain di sisi Nabi Saw dengan tombak-tombak mereka, maka Umar masuk lalu mengambil kerikil dan melempari mereka. Nabi Saw bersabda, "Biarkanlah mereka wahai Umar'." Ali memberi tambahan, “Abdurrazzaq menceritakan kepada kami, Ma'mar telah menggambarkan kepada kami, di masjid'

Berdasarkan ayat Al Quran dan hadits diatas terbukti bahwa pendidikan jasmani telah ditanamkan dalam ajaran Islam sejak dulu (Nopel, 2020). Berbagai macam hal yang berkaitan dengan pendidikan jasmani telah tertulis dan dianjurkan oleh Islam (Kahar, 2018). Sifat-sifat tubuh seperti kuat, perkasa, sehat menggambarkan bahwa kondisi jasmani seseorang sangat penting untuk memegang kekuasaan pada jaman peperangan. Manusia yang memiliki jasmani yang baik akan mampu menghadapi lawan dan memimpin pasukannya untuk meraih kemenangan. Pendidikan jasmani yang telah diterapkan yaitu berupa peningkatan kekuatan tubuh serta menjaga kesehatan dengan cara membuat obat untuk menyembuhkan berbagai macam penyakit. 
Sifat Nabi Muhammad SAW telah banyak dijadikan sebagai pedoman dalam pendidikan Islam. Dalam hadits disebutkan bahwa sunah Rasulullah SAW yang dijadikan sebagai landasan pendidikan Islam yaitu berupa perkataan, perbuatan, dan pengakuan Rasulullah SAW. Ajaran Islam yang berpedoman terhadap sifat nabi/rasul sering disebut ajaran profetik (Zuhri, 2020). Umat Islam senantiasa berpedoman dan mengikuti ajaran nabi karena ketaqwaan nabi yang luar biasa terhadap Tuhan. Kepemimpinan profetik dalam perspektif manajemen pendidikan Islam merupakan bagian dari sebuah tanggung jawab semua umat Islam khususnya orang-orang yang tekun, cerdas, dan pandai serta mereka semua wajib untuk mencari sebuah pencapaian baru yang dapat menjadikan umat Islam sebagai alternatif utama dan sebagai saksi sejaran di tengah kebodohan pada zaman modern, yang mana rintangan dan tantangan semakin menghalangi berbagai sudut maupun lapisan (Dewi, Hidayatullah, \& Raini, 2020).

Pada jaman sejarah, umat Islam sangat giat untuk berlatih sebagai bekal dalam berperang melawan musuh. Mereka berlatih memanah, menombak, dan membentuk fisik yang kuat untuk berperang. Hal tersebut merupakan salah satu contoh bahwa Islam sejak dulu menerapkan pendidikan jasmani dalam kehidupan sehari-hari. Ajaran Islam yang masih terus berkembang pada jaman dahulu dapat menjadi bukti bahwa pendidikan jasmani yang telah diterapkan dapat mempertahankan umat Islam dari berbagai macam bahaya. Pendidikan jasmani sangat berjasa dalam perkembangan ilmu pendidikan Islam dan membawa kehidupan manusia kearah yang lebih baik (Kandiri \& Mahmudi Bajuri, 2020). Jika pendidikan jasmani tidak diterapkan dalam kehidupan manusia, maka Islam tidak akan berkembang hingga saat ini. Terdapat tiga dasar religiositas Islam, yang implikasinya sebagaimana hadis Nabi SAW: "Iman adalah membenarkan dengan hati, mengikrarkan dengan lisan, dan mengamalkan dengan anggota badan".

Sebagian besar ahli pendidikan sepakat bahwa pentingnya menggerakan anggota badan dapat menumbuhkan potensi, baik jasmani, intelektual, tingkah laku, maupun sosial. Beberapa manfaat pendidikan jasmani menurut islam yaitu meningkatkan nilai jasmaniah, intelektual, sosial, pendidikan, moral, inovasi, dan personalitas (Rochim, 2017). Nilai jasmaniah berkaitan dengan kondisi fisik manusia yang dapat bergerak aktif dalam berbagai aktivitas. Nilai intelektual berkaitan dengan tumbuh kembang akal seseorang untuk berfikir. Nilai sosial berkaitan dengan cara bersosialisasi seseorang dengan adanya berbagai kegiatan dalam pendidikan jasmani. Melalui pendidikan jasmani, manusia dapat dilatih untuk memahami suatu konsep yang hibungannya dengan moral, mengekspresikan potensi serta kreativitasnya berkaitan dengan nilai inovasi, serta bisa menyikapi berbagai macam hal dalam meningkatkan nilai personalitas.

Pendidikan jasmani dalam pelaksanaannya yaitu menggerakan anggota badan agar meningkatkan kebugaran jasmani dan meningkatkan kesehatan tubuh. Pada saat pelaksanaan pendidikan jasmani, banyak masyarakat yang selalu berdoa sebagai bukti bahwa kegiatan yang mereka lakukan merupakan suatu amalan atas seijin Allah SWT. Tidak hanya itu, ketika melaksanakan shalat sebagai bentuk ibadah kepada Allah SWT, manusia juga melakukan gerakan secara berulang sehingga dapat dikategorikan bahwa pelaksanaan shalat juga merupakan salah satu wujud dari pendidikan jasmani. Hal tersebut dapat dibuktikan bahwa shalat memberikan manfaat bagi tubuh antara lain memperlancar peredaran darah, memperlancar sistem pencernaan, membuat tubuh rileks, pengendalian otot perut, meredakan nyeri punggung dan nyeri sendi.

Islam memandang bahwa jasmani merupakan struktur kepribadian menusia dalam bentuk potensial. Islam mengatakan bahwa manusia bersifat material dan berbentuk kasar, serta tidak kekal yang membutuhkan sesuatu yang dapat mempertahankan kehidupannya. Pendidikan Islam yang dilaksanakan dalam kehidupan sehari-hari sangat erat hubungannya dengan pendidikan jasmani, baik masa lalu maupun saat ini. Berbagai kegiatan yang dianjurkan oleh Allah dalam bentuk pendidikan Islam memiliki manfaat masing-masing bagi kesehatan jasmani, sehingga dapat dikatakan bahwa pendidikan jasmani merupakan bagian dari pendidikan Islam. 


\section{KESIMPULAN}

Berdasarkan uraian di atas dapat disimpulkan bahwa pendidikan Islam sangat penting bagi kehidupan manusia karena digunakan sebagai pedoman dalam menentukan berbagai aspek kehidupan. Salah satu aspek kehidupan yang sangat penting yaitu tentang jasmani dalam diri seseorang. Jasmani merupakan bagian tubuh yang saling melengkapi dengan rohani. Pengembangan jasmani dapat dilakukan dengan cara melaksanakan pendidikan jasmani. Landasan religius dalam pendidikan jasmani membuktikan bahwa pendidikan agama Islam saling berhubungan dengan pendidikan jasmani dan saling melengkapi satu sama lain dalam mendukung kehidupan manusia sebagai khalifah di bumi. Jika jasmani seseorang tidak dalam keadaan baik, maka manusia tidak akan sempurna dalam menjalankan segala bentuk amalan ibadah. Oleh karena itu, pendidikan jasmani sangat penting sebagai pendukung dalam pendidikan Islam. Berdasarkan pembahasan diatas, perlu dilakukan pengkajian lebih dalam lagi mengenai pendidikan Islam dalam perspektif bidang lain seperti aspek yuridis dan medis agar pembaca mengetahui lebih dalam mengenai makna pendidikan Islam jika dilihat dari berbagai bidang.

\section{UCAPAN TERIMAKASIH}

Puji syukur kami panjatkan terhadap Tuhan Yang Maha Esa atas segala rahmat dan hidayahnya, sehingga kami dapat menyelesaikan karya tulis ini. Tidak lupa juga kami sampaikan terimakasih kepada semua pihak yang telah membantu dalam proses penyusunan karya tulis ini.

\section{DAFTAR PUSTAKA}

Creswell, J. W. (2015). Penelitian Kualitatif dan Desain Riset. Yogyakarta: Pustaka Pelajar.

Dewi, E. R., Hidayatullah, C., \& Raini, M. Y. (2020). Konsep Kepemimpinan Profetik. Al-Muaddib: Jurnal Ilmu-Ilmu Sosial Dan Keislaman, 5(1), 147-159.

Frandika, E., Suroso, \& Suharto, A. W. B. (2019). Self-Actualization of the Main Characters in the Perempuan Berkalung Sorban by Abidah El Khalieqy: Psychological Study of the Abraham Perspective Maslow Literature.

Kahar, S. (2018). PENDIDIKAN JASMANI DAN PENGARUHNYA TERHADAP PENDIDIKAN ISLAM (TINJAUAN DALAM PERSPEKTIF FILSAFAT PENDIDIKAN ISLAM). ITQAN, 9(2), 61-80.

Kandiri, \& Mahmudi Bajuri. (2020). Pendidikan Islam Ideal. Jurnal Pendidikan Islam Indonesia, 4(2), 157-172. https://doi.org/10.35316/jpii.v4i2.187

Krippendorff, K. (1993). Analisis Isi: Pengantar Teori dan Metodologi. Jakarta: Rajawali Pers.

Lazuardi. (2014). Hadis Pendidikan: Penelusuran Akar Pendidikan Jasmani Dalam Hadis. Forum Paedagogik Edisi Khusus Juli-Desember 2014 139, pp. 1-27.

Ma'zumi, Syihabudin, \& Najmudin. (2019). PENDIDIKAN DALAM PERSPEKTIF AL-QUR'AN DAN AL-SUNNAH : Kajian Atas Istilah Tarbiyah, Taklim, Tadris, Ta'dib dan Tazkiyah. TARBAWY: Indonesian Journal of Islamic Education, 6(2), 193-209. https://doi.org/10.17509/t.v6i2.21273

Mujahir. (2015). Jasmani Manusia Dalam Perspektif Para Ahli Pendidikan. Jurnal QATHRUNÂ, 2(2), 87-120.

Mulya, G., Fitri, E., Syaflin, H. M., Akbar, H. M., Sembiring, I., \& Nopianto, W. (2015). Revitalisasi Pendidikan Jasmani dan Olahraga di Indonesia pada Pembangunan Jangka Menengah 2015-2019. In H. M. Syaflin, W. Nopianto, \& H. M. Akbar (Eds.), Seminar Nasional Keolahragaan (p. 365). Jakarta: Fakultas Ilmu Keolahragaan.

Naqiyah, Wachid Bambang Suharto, A., \& Supriyanto. (2019). Rumah Kreatif Wadas Kelir as a model of Colportage that Improves the Prosperity of the Community Based on Religious Literacy. Advances in Social Science, Education and Humanities Research, 436, 11341139.

Nopel, P. (2020). Perspektif Al- Qur ' an Universitas Islam Negeri ( Uin) Sultan Syarif Kasim Riau 
1441 H / 2020 M. UIN Sultan Syarif Kasim Riau.

Partanto, P. A., \& Al-Barry, M. D. (1994). Kamus Ilmiah Populer. Surabaya: Arloka.

Rochim. (2017). Konsep Pendidikan Akal Dalam Perspektif Hamka. PANCAWAHANA: Jurnal Studi Islam, 2(2), 59-83.

Saryono, D. (2018). PROSIDING KBS3 FINAL. In Wagiran, Z. Fahmy, M. B. Siroj, I. Baehaqi, \& Suseno (Eds.), Pendidikan dan Pembelajaran di Era Disrupsi: Dimanakah Tempat Pembelajaran Sastra Indonesia? (pp. 23-51). Semarang: Universitas Negeri Semarang.

Siti Maesaroh. (2017). Nilai-Nilai Pendidikan Jasmani (Kajian Tafsir Al-Baqarah Ayat 247)Universitas Islam Negeri (Uin). UIN Syarif Hidayatullah Jakarta.

Suharto, A. W. B., Waluyo, H. J., Pradopo, R. D., \& Suyitno. (2017). INTELLECTUAL RELIGIOSITY OF ISLAMIC BOARDING SCHOOL IN A. MUSTOFA BISRI'S POETRY. Jurnal Kebudayaan Islam, 15(2), 324-344. https://doi.org/10.24090/ibda.v15i2.2017.pp324-344

Suharto, A. W. B., Waluyo, H. J., Pradopo, R. D., \& Suyitno, S. (2018). THE VALUES OF ARCHIPELAGIC ISLAM IN A. MUSTOFA BISRI'S POETRY. IBDA ‘ Jurnal Kajian Islam Dan Budaya, 16(2), 201-223. https://doi.org/10.24090/ibda.v16i2.1746

Zuhri. (2020). Kepemimpinan Profetik di Era 4.0. SALIMIYA : Jurnal Studi Ilmu Keagamaan Islam, 1(1), 115-135. Retrieved from https://ejournal.iaifa.ac.id/index.php/salimiya

\section{BIOGRAFI PENULIS}

Penulis merupakan salah satu guru pendidikan jasmani yang mengajar di MAN 3 Banyumas. Saat
ini, penulis sedang menempuh pendidikan yang lebih lanjut di salah satu universitas yaitu
Universitas Islam Negeri Prof. K. H. Saifuddin Zuhri yang berada di Kota Purwokerto.

